Präparat: Das ausgeschnittene Stück fand sich durchsetzt von zahllosen kleinsten, aber mit bloßem Atge gat erkennbaren, silberglänzenden Kügelchen, die hauptsächlich in dem $1 / 2-1 \mathrm{~cm}$ dicken Unterhautfettgewebe, aber auch noch in der Fascie und in den tiefsten Schichten der Haut sich fander, Papillarkörper und Epidermis dagegen ganz freiließen. Die Muskulatur war, wie man sich bei der Operation und auf einem nach der Operation aufgenommenen zweiten Röntgenbild taberzeugen konnte, ebenfalls ganz

Aus der Chirurgischen Abteilung des Katharinen-Hospitals in Stuttgart. . (Direktor: Ober-Med.-Rat Dr. v. Burckhardt.)

\section{Ueber das Vorkommen von metallischem Quecksilber im menschlichen Körper.}

\author{
Von Dr. Walther Schmidt.
}

Vor kurzem hatten wir Gelegenheit, hier einen Fall zu beobachten, bei dem sich metallisches Quecksilber in der Menge von etwa $0,5 \mathrm{~g}$ in Form von makroskopischen Kügelchen auf etwa handtellergroßer Fläche im Unterhautzellgewebe und in der Fascie vorn mitten am rechten oberschenkel eines jungen Mannes fand. Da wir bis jetzt nicht in Erfahrung bringen konnten, auf welche Weise das Queeksilber in seinen Körper gelangt war, und da überhaupt das Vorkommen von metallischem Quecksilber in solcher Menge im Körpergewebe ungewöhnlich zu sein scheint, veröffentlichen wir den Fall. Die Krankengeschichte ist kurz folgende:

Der 22jährige Ankuppler G. W., kam am 23. Juli 1902 unter die Räder eines Eisenbahnwagens. Dabei wurde ihm der linke Oberschenkel hoch oben abgefahren und der linke Oberarm kompliziert gebrochen. Der große Blutverlust, sowie Diarrhöen und eine doppelseitige Parotitis in der ersten Zeit nach der Verletzung, die die Ernährung durch den Mund erschwerten, gaben Anlaß, daß er zahlreiche Salzwasserinfusionen und Kampferöleinspritzungen erhielt. Die Injektionen erfolgten fast alle unter die Haut des rechten Oberschenkels und des rechten Armes. Der Oberschenkelstumpf, der primär wegen des Collapses nicht regelrecht zugerichtet werden konnte, machte Nachoperationen (Stumpfresektionen) am 14. August und 14. Oktober notwendig. Am 21. Januar 1903 wurde W. aus dem Spital entlassen. Im Mai 1903 erhielt er ein Ersatzglied. Seither ist er als Schreiber auf der Güterstelle der Staatseisenbahn in Stuttgart angestellt.

Seit der Entlassung aus dem Spital hatte er, wie er jetzt angibt, eine harte Stelle mitten vorn am rechten Oberschenkel bemerkt, die im Herbst 1905 aufbrach. Die spärlich absondernde Fistel schloB sich bald, bald aber entstand daneben wieder eine neue Fistel, die sich wieder schlo $\beta$ und wieder aufbrach u.s. f. Die Belästigung durch die Fistel führte W. zum Bahnarzt, Herrn Dr. Feldmann, der ihn längere Zeit behandelte und ihn dann ins Spital wies, weil W. vermutete, er habe von den Einspritzungen im Jahre 1903 her vielleicht eine abgebrochene Hohlnadel im Bein.

Bei der Aufnahme am 20. Juni 1906 war bei dem gesund aussehenden und gut genährten Manne, der mit seinem Ersatzglied gut gehen und seinen linken Arm unbehindert gebrauchen konnte, ungefahr in der Mitte der Vorderseite des rechten Oberschenkels eine etwa drei Finger breite und daumenlange Infiltration der Haut and der darunter liegenden Schichten zu bemerken. Das Infiltrat war nicht deutlich abgegrenzt, gegen die Muskulatur nicht, gegen den Knochen gut verschieblich und nicht druckempfindlich. Die bedeckende Haut war von einer feinen, spärlich serös-eitriges Sekret absondernden Fistel durchlöchert und zeigte mehrere frische, bläulichrötliche Fistelnarben, im übrigen normales Aussehen. Auf dem Röntgenbild (siehe das beigefügte Bild) war nichts von der von $W$. vermuteten Hohlnadel zu sehen, wohl aber im Bereich der Infiltration zahllose rundliche Schatten von $1-3 \mathrm{~mm}$ Durchmesser, ein Bild wie das eines Schrotschusses mit feinstem Schrot. Daraufhin wurde am 22. Juni das ganze Infiltrat samt bedeckender Haut und dem zugehörigen Stück der Fascia lata ausgeschnitten, der Defekt durch Fascien- und Hautnaht geschlossen. Nach glatter Heilung wurde W. am 17. Juli 1906 wieder entlassen.

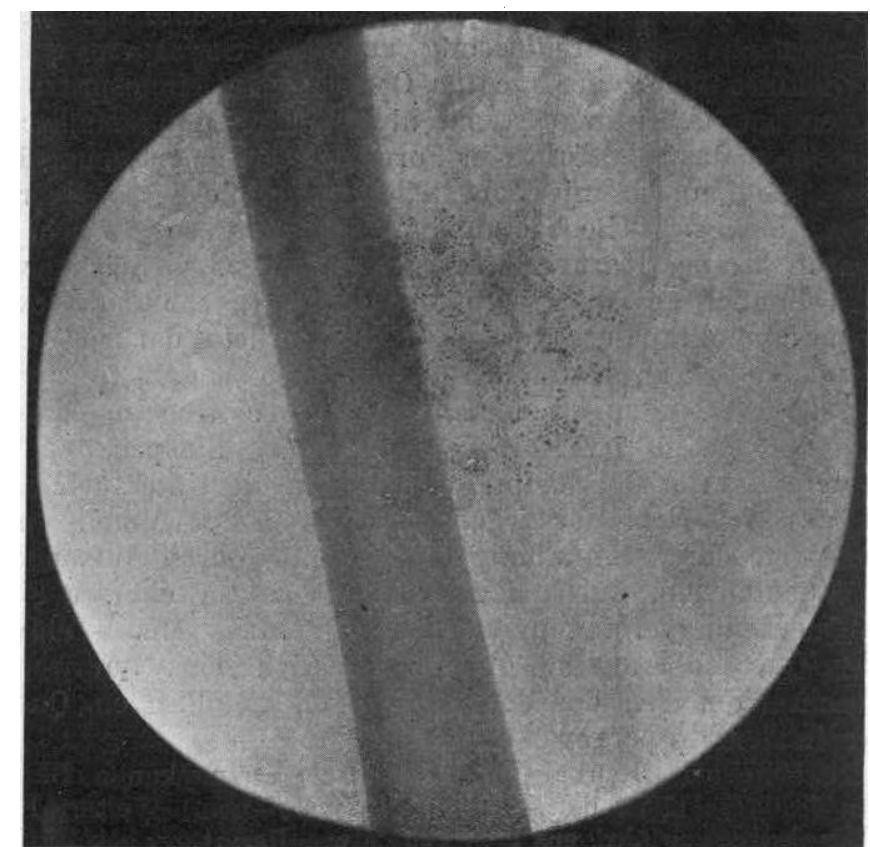

frei. Die Gewebsschichten, in denen die Fremdkörper lagen, waren in mäßigem Grade narbig verändert. Die Kügelchen saßen vielfach so lose, daß sie aus den Schnitten herausrollten. Sie waren schon durch ihren Silberglanz und ihre Beweglichkeit ohne weiteres als reines metallisches Quecksilber erkennbar. Außerdem gaben sie, mit Jod erhitzt, das scharlachrote Quecksilberjodid. Die Gesamtmenge des Quecksilbers war auf mindestens $0,5 \mathrm{~g}$ zu schätzen. Sonst war, wie Röntgenbilder zeigten, im Körper nirgends Quecksilber abgelagert.

Wir haben uns nun bisher vergeblich bemüht zu ermitteln, woher das Quecksilber bei unserem Kranken stammt.

Solange W. bei uns 1902/3 in Behandlung stand, kamen Quecksilberpräparate bei ihm nicht zur Verwendung, auber der zur Desinfektion der Haut und der Pravazspritzen, vielleicht auch einmal zur Abspülung der Wunde am linken Bein benützten $1 \%$, Sublimatlösung. Davon kann wohl das Quecksilber nicht stammen. Auch Herr Dr. Feldmann, der den Kranken seit dem letzten Winter behandelte, hat, wie er uns sagte, kein quecksilberhaltiges Mittel bei ihm angewandt. Vor seiner Verleizung hat W. im Jahre 1900 eine Lungenentzündung und einen Typhus gehabt. Es ist möglich, daB er damals Calomel innerlich bekommen hat. Es ist aber nicht anzunehmen, daß davon das Quecksilber in seinem rechten Oberschenkel herrührt. Denn es ist bis jetzt nichts darüber bekannt, dạ sich aus dem durch den Mund gegebenen Calomel metallisches Quecksilber in größeren Mengen in den Geweben des Körpers abscheidet. Außerdem wäre garnichtverständlich, warum das sich aus im Körper kreisenden Quecksilberverbindungen etwa abseheidende Metall sich gerade an diesem einen Punkte des Körpers niederschlagen sollte. In anderweitiger ärztlicher Behandlung will W. nicht gestanden haben; insbesondere bestreitet er auf das bestimmteste, jemals eine syphilitische Erkrankung gehabt zu haben; auch haben wir bei seinem letzten Spitalaufenthalt vergeblich nach luetischen Erscheinungen bei ihm gesucht. Natürlich ist es trotzdem: möglich, dal er doch irgend einmal eine antiluetische Kur durchgemacht und bei dieser Gelegenheit irgend ein Quecksilberpräparat am rechten Oberschenkel eingespritzt bekommen hat. Jedenfalls liegt die Vermutung am nächsten, daf das Quécksilber an den Ort, an dem wir es fanden, direkt durch eine Injektion ins subcutane Gewebe hingebracht worden ist. Die Beschränkung des Quecksilbers auf diesen énèn Punkt im ganzen Körper macht das 
wahrscheinlich. Man ist auch nach der Krankengeschichte versucht, den Quecksilberfund mit den Injektionen in Zusammenhang zu bringen, die W. im Jahre 1903 gerade vorn am rechten Oberschenkel in grober Anzahl unter die Haut erhalten hat. Aber ein Quecksilberpräparat ist damals - abgesehen von der Sublimatlösung zur Desinfektion - ja garnicht benutzt worden, eine Infiltration am Oberschenkel damals auch nicht aufgefallen. So ist es immer noch am wahrscheinlichsten, daß W. eben doch, entgegen seiner Angabe, von irgend jemand nach seiner Entlassung aus dem Spital ein quecksilberhaltiges Mittel am rechten Oberschenkel eingespritzt bekommen hat. Allerdings ist mir nicht bekannt, ob metallisches Quecksilber, das man, etwa in Form des Oleum cinereum, einspritzt, sich an der Injektionsstelle in der Weise, wie wir es fanden, ablagert. Beobachtungen scheinen, soweit ich die Literatur kenne, darüber nicht vorzuliegen, vielleicht weil die gewöhnlich gewählten Injektionsstellen (Gesäß und Rücken) seltener photographiert werden. Ebenso scheint darüber nichts bekannt, ob und unter welchen Bedingungen sich aus injizierten Quecksilberverbindungen metallisches Quecksilber in makroskopischer Menge im Körper am Ort der Einspritzung abscheidet. Es gibt überhaupt, so zahlreich die Untersuchungen über das Schicksal des irgendwie (durch den Mund, durch Einatmung, durch Einreibung in die Haut, durch Aufsaugung von Wundflächen, durch Einspritzung ins Gewebe) in Form von Quecksilberverbindungen oder als reines Metall einverleibten Quecksilbers sind, doch, soviel ich sehe, nur wenige Beobachtungen über das Vorkommen von metallischem Quecksilber in den Körpergeweben.

In Hufelands Journal der praktischen Arzneykunde Bd. LI, Berlin 1820, S. 117 ist ein solcher Fall beschrieben. Weitere Fälle hat $\nabla$ irchow, der übrigens selbst nie etwas Derartiges gesehen hat, wie er im XV. Bd. seines Archivs, S. 224 erwähnt, 1860 aus der Literatur gesammelt (Archiv für pathologische Anatomie etc. Bd. XVIII, S. 364).

In allen diesen Fällen handelt es sich um das Vorkommen von makroskopischen Mengen von reinem Quecksilber in den Knochen von menschlichen Leichen. Die Herkunft des Quecksilbers ist nicht immer erwähnt, doch waren es in der Mehrzahl der Fälle Syphilitiker, denen, wie man wohl annehmen darf, größere Mengen von Quecksilberpräparaten einverleibt worden waren. Aus neuerer Zeit konnte ich keine derartigen Beobachtungen auffinden, ebensowenig Mitteilungen über das Vorkommen von metallischem Quecksilber in makroskopischen Mengen in den Weichteilen des Körpers, Haut und Schleimhaut ausgenommen.

Vielleicht gibt unser Fall Anlaf, daß man da oder dort der Frage des Vorkommens von metallischem Quecksilber im menschlichen Körper wieder näher tritt. 